\title{
Bioanalysis
}

\section{Novel drug and soluble target tolerant antidrug antibody assay for therapeutic antibodies bearing the P329G mutation}

\begin{abstract}
Aim: Bridging immunoassays for detection of antidrug antibodies (ADAs) are typically susceptible to high concentrations of residual drug. Sensitive drug-tolerant assays are, therefore, needed. Materials \& methods: An immune complex assay to detect ADAs against therapeutic antibodies bearing Pro329Gly mutation was established. The assay uses antibodies specific for the Pro329Gly mutation for capture and human soluble Fc $\gamma$ receptor for detection. Results: When compared with a bridging assay, the new assay showed similar precision, high sensitivity to IgG1 ADA and dramatically improved drug tolerance. However, it was not able to detect early (IgM-based) immune responses. Conclusion: Applied in combination with a bridging assay, the novel assay serves as orthogonal assay for immunogenicity assessment and allows further characterization of ADA responses.
\end{abstract}

First draft submitted: 11 March 2017; Accepted for publication: 27 April 2017; Published online: 18 May 2017

Keywords: antidrug antibody • drug tolerance $\bullet$ ELISA $\bullet$ FcyRl $\bullet$ immune complex assay - immunogenicity $\bullet$ safety assessment $\bullet$ suppressed Fc effector functions $\bullet$ target interference

Bridging immunoassay (Figure $1 \mathrm{~A}$ ) is currently the predominant assay format for immunogenicity assessment in preclinical and clinical studies [1-3]. The assay allows for high-throughput testing with high sensitivity and easy implementation [4]. However, the bridging assay can be interfered by the presence of oligomeric soluble target, which can serve as a 'bridge' thus reducing specificity by providing a false-positive result [5-8], or residual drug, which can form an immune complex with antidrug antibodies (ADAs), thereby reducing sensitivity by providing a false-negative result $[6,9,10]$. Thus, there is a need for alternative assay formats that can overcome these potential weaknesses of the bridging design [11].

We recently described a novel assay with an orthogonal detection method based on digoxigenin (Dig) labeled ectodomain (extracellular ligand-binding domain) of the human Fcy receptor I (hsFcyRI; see
Figure 1B) [12]. In this assay, the secondary signal detection provides evidence that the assay signal is caused by an IgG1 antibody - a clear advantage over the bridging assay, which would detect any entity that is able to bind two drug molecules, such as an oligomeric soluble target. The hsFc $\gamma$ RI-based assay reliably detected human and Cynomolgus monkey IgG-ADAs against therapeutic monoclonal antibodies (mAbs) with suppressed Fc effector functions, such as those bearing Pro329Gly (PG) or Leu234Ala and Leu235Ala (LALA) substitutions in the Fc region [12-14]. The assay requires only one free ADA Fab fragment, as opposed to two in the bridging format, and hence it was less susceptible to the presence of residual drug. Yet, the interference by residual drug cannot be completely excluded by the use of a hsFc $\gamma R I-$ based detection method because the capture method still requires a free drug-binding site on the ADA molecule.
Uwe Wessels*,1, Eginhard Schick ${ }^{2}$, Mirko Ritter ${ }^{3}$, Frank Kowalewsky ${ }^{3}$, Julia Heinrich ${ }^{1}$ \& Kay Stubenrauch ${ }^{1}$ 'Pharmaceutical Sciences, Pharma Research \& Early Development, Roche Innovation Center Munich, Nonnenwald 2, 82377 Penzberg, Germany

2Pharmaceutical Sciences, Pharma Research \& Early Development, Roche Innovation Center Basel, Grenzacherstrasse 124, 4070 Basel, Switzerland

${ }^{3}$ Roche Diagnostics GmbH,

Roche Innovation Center Munich, Nonnenwald 2, 82377 Penzberg, Germany

*Author for correspondence: Tel. . + 498856603814 Fax: + 498856603268 uwe.wessels@roche.com 
Therefore, we pursued the further development of the hsFc $\gamma$ RI-based assay, aiming at achieving even better tolerance toward high concentrations of residual drug. The improved assay format presented in this report can complement the bridging assay in immunogenicity assessment of therapeutic $m A b s$ bearing the PG-substitution in the Fc region, which are used in several clinical development projects $[12,14,15]$. The assay principle, which, in similar design has been previously described for the preclinical assessment of drug-ADA complexes [11,16-18], involves the capture of a drug-ADA complex by an immobilized antibody that is specific for the PG-mutagenized Fc region. Bound immune complexes are detected using hsFc $\gamma \mathrm{RI}$ (Figure 1C). Since the hsFc $\gamma$ RI does not bind to the PG-modified Fc region of the drug (Figure 1D; [12]) and the anti-PG capture antibody, in turn cannot bind to the wild-type $\operatorname{IgG}$ (wtIgG; Figure 1E), the detection is specific for the drug-ADA complex. We therefore expect that the assay is intrinsically insensitive to even high drug concentrations in the matrix. Moreover, the absence of residual drug may negatively affect the assay sensitivity, as it may lead to low levels of drugbound ADA in the sample. The presented assay format therefore includes a sample pre-incubation step with an excess of free drug, which ensures the presence of drug-ADA complexes. Like the previously described assay. the new hsFcrRI-PG assay benefits from using $\mathrm{hsF} c \gamma \mathrm{RI}$ as detection reagent, ensuring that the serum factor that is responsible for a signal is indeed an antibody.

In this article, we describe the developed hsFc $\gamma \mathrm{RI}-\mathrm{PG}$ assay format and compare it with a standard bridging assay, including assay qualification, assessment of drug tolerance and the applicability of the hsFc $\gamma$ RI-PG assay to immunogenicity testing in clinical samples.

\section{Materials \& methods}

\section{Chemicals, reagents \& equipment}

All antibodies were produced by Roche Diagnostics $\mathrm{GmbH}$ (Penzberg, Germany) and were stored in aliquots at $-80^{\circ} \mathrm{C}$ until use [19]. Anti-X $\mathrm{mAb}$ is a recombinant human PG-modified IgG1 targeting protein $\mathrm{X}$. The capture antibody against the PG modification was generated by immunization of mice with human monoclonal IgG1 bearing the PG and LALA substitutions within the Fc domain. Briefly, hybridomas were generated by fusion of splenocytes of immunized mice with P3 $\times$ 63-Ag8.653 myeloma cells. Hybridomas were screened for production of $\mathrm{mAb}$ binding to human IgG containing the PGLALA mutation using ELISA. Cross-reactivity with human wild-type (WT) IgG was tested by ELISA and cross-reactive mAbs were excluded from further evaluation. hsFc $\gamma$ RI was purchased from R\&D Systems (MN, USA). Biotin (Bi) - and Digoxigenin (Dig)-labeling of antibodies and hsFc $\gamma$ RI were performed in-house.

Anti-Dig polyclonal sheep Ab-Fab-fragments coupled with horseradish peroxidase (anti-Dig-SFab-HRP), peroxidase substrate 2,2'-azino-bis-3-ethylbenzthiazoline-6-sulphonic acid (ABTS) and phosphate-buffered saline were from Roche Diagnostics $\mathrm{GmbH}$. Low Cross Buffer ${ }^{\circledR}$ was from Candor Bioscience GmbH (Wangen, Germany). Washing buffer contained $0.05 \%$ Tween-20 (Calbiochem, Darmstadt, Germany) and 0.0002\% 5-bromo-5-nitro-1,3-dioxane (Bronidox; Sigma-Aldrich, Steinheim, Germany) in phosphate-buffered saline. Human pooled serum (HPS) and individual human serum samples collected in all cases from healthy individuals were obtained from Sera Laboratory International Ltd. (Haywords Heath, UK).

Streptavidin (SA) coated 96-well ELISA microtiter plates (SA-MTP) were provided by Roche Diagnostics GmbH. Biacore ${ }^{\circledR}$ T200 instrument, CM5 sensor chip and amine coupling kit were obtained from GE Healthcare Life Science (Uppsala, Sweden).

\section{Specificity of anti-PG \& hsFc $\gamma R$ I binding}

The specificity of hsFc $\gamma R I$ binding was determined by surface plasmon resonance using a Biacore T200 instrument. The anti-PG antibody and hsFc $\gamma \mathrm{RI}$ (diluted to $10 \mu \mathrm{g} / \mathrm{ml}$ in $10 \mathrm{mM}$ acetate buffer, $\mathrm{pH} 4.5$ ) were directly immobilized to a CM5 sensor chip using amine coupling kit (achieved immobilization levels were approximately 8000 relative units for the antiPG antibody and 5000 relative units for the hsFc $\gamma \mathrm{RI})$. After immobilization, an antibody sample $(10 \mu \mathrm{g} / \mathrm{ml})$ was injected for $60 \mathrm{~s}$ at a flow rate of $10 \mu \mathrm{l} / \mathrm{min}$ and temperature of $25^{\circ} \mathrm{C}$. Resonance signal was measured $80 \mathrm{~s}$ after the start of injection. Following the analysis, the chip was regenerated by injection of Tris-HCL buffer, $\mathrm{pH} 2.0$ for $30 \mathrm{~s}$.

\section{Bridging ADA assay}

ADAs against $m A b$ anti-X were detected by a one-step ELISA (Figure 1A). Affinity-purified anti-idiotypic polyclonal rabbit antibody $(\mathrm{Ab})$ directed against the complementarity determining region of $\mathrm{mAb}$ anti-X served as calibration standards and QC samples (prepared in HPS). Reagents and samples were incubated at room temperature with shaking at $450 \mathrm{rpm}$.

Samples were diluted tenfold in Low Cross Buffer ${ }^{\circledR}$ containing Bi- and Dig-labeled $\mathrm{mAb}$ anti-X (each at $1.0 \mu \mathrm{g} / \mathrm{ml}$ ), incubated overnight and then transferred to a SA-MTP $(2 \times 100 \mu \mathrm{l}$ of each sample in duplicate wells). After 1-h incubation, the plate was washed three-times followed by aspiration, $100 \mu \mathrm{l}$ anti-Dig- 


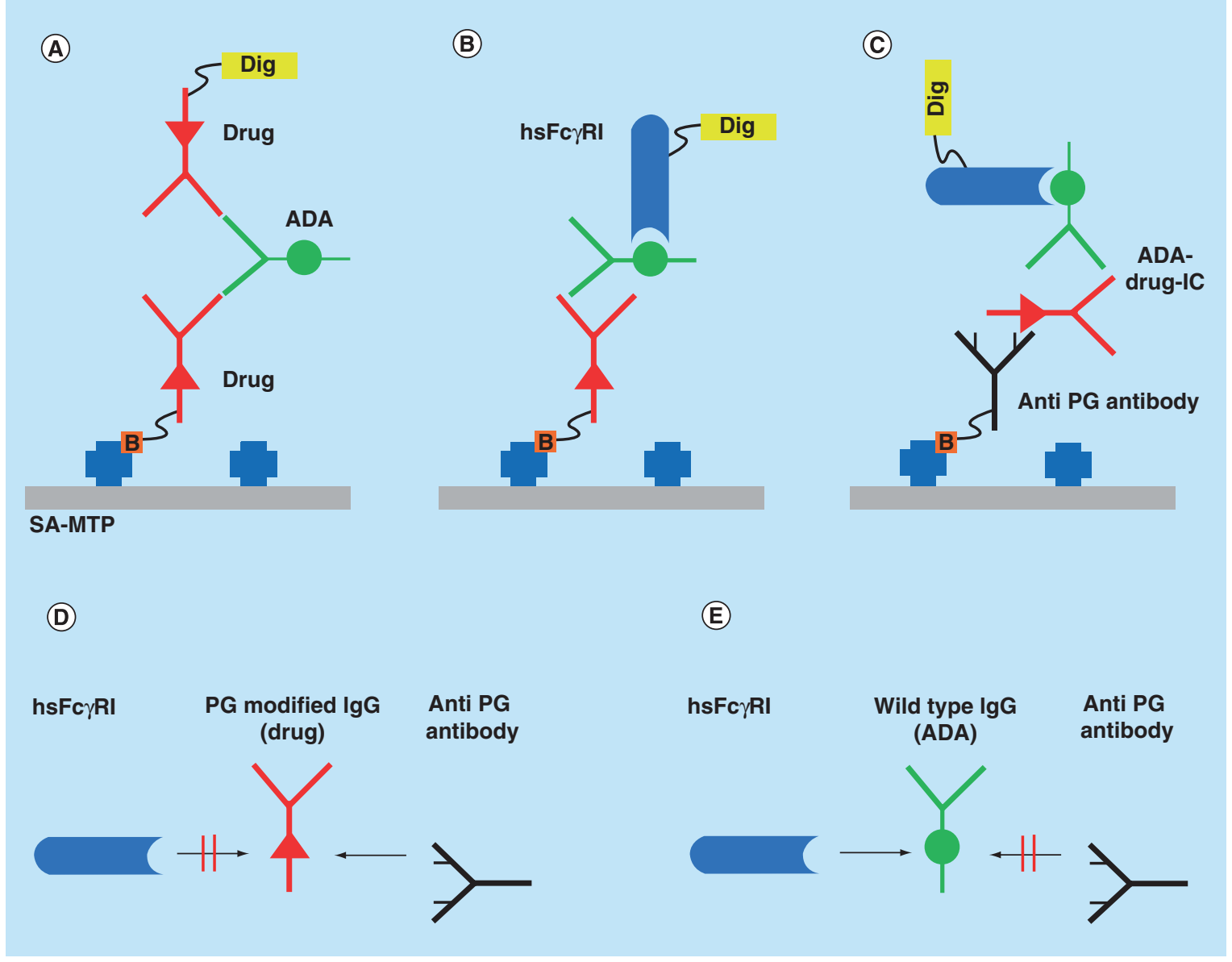

Figure 1. Principles of the bridging, human soluble Fcy receptor I based and human soluble Fcy receptor I-Pro329Gly assays. (A) In the bridging assay, the two antigen-binding sites of ADA couple immobilized drug (drug-B) with digoxigenylated drug (drug-Dig) used for detection. (B) In the hsFc $\gamma$ RI-based assay, ADA is captured by immobilized drug and then detected using digoxigenylated hsFc $\gamma \mathrm{RI}$ (hsFc $\gamma \mathrm{RI}-\mathrm{Dig}$ ). (C) In the hsFc $\gamma \mathrm{RI}-\mathrm{PG}$ assay, PG-modified drug-ADA complex (IC) is captured by immobilized anti-PG antibody and the bound ADA is detected using FcyRI-Dig. (D) Anti-PG antibody but not hsFcyRI can bind to a PG-modified drug. (E) hsFc $\mathrm{RI}$ but not anti-PG antibody can bind to wild-type IgG (e.g., ADA).

ADA: Antidrug antibody; B: Biotin; Dig: Digoxigenin; hsFc RI: Human soluble Fc receptor I; PG: Pro329Gly substitution; SA-MTP: Streptavidin-coated microtiterplate.

S-Fab-HRP conjugate $(25 \mathrm{mU} / \mathrm{ml})$ was added to each well and the plate was incubated for $1 \mathrm{~h}$. Thereafter, the plate was washed three-times followed by aspiration, ABTS (100 $\mu$ l per well) was added and the color reaction was photometrically assessed at $405 \mathrm{~nm}$ (reference wavelength $490 \mathrm{~nm}$ ) at a time when the highest standard reached an optical density (OD) of 1.8-2.2. Samples were measured in duplicates and mean absorbance values were calculated. Measurements were considered valid if the precision of the assay signal per duplicate was $\leq 20 \%$ of the coefficient of variation (CV).

The screening and the confirmatory cut-point was determined nonparametrically according to Shankar et al. [20] by analyzing 100 individual blank serum samples (in the absence and the presence of spiked
$\mathrm{mAb}$ anti-X). To calculate plate-specific cut-points, the plate specific blank value was multiplied by the assay specific normalization factor. In this study, two plates were used to generate data. The corresponding cut-points were 0.061/0.062 OD. Each sample was analyzed three-times in duplicates. Clinical sample analysis followed the three-tiered approach described in the literature [20].

\section{hsFcyRI-PG assay}

The assay was developed as a three-step solid phase ELISA (Figure 1C). A conjugate of human wtIgG and human PG-modified IgG was used as calibration standard and for preparation of QC samples. (prepared in HPS). Reagents and samples were incubated at room temperature with shaking at $450 \mathrm{rpm}$. 
First, Bi-labeled anti-PG antibody $(2 \mu \mathrm{g} / \mathrm{ml}, 100 \mu \mathrm{l}$ per well) was bound to a SA-MTP. In the meantime, study and QC samples were pre-incubated under shaking (500 rpm) for $30 \mathrm{~min}$ in Low Cross Buffer ${ }^{\circledR}$ containing $1 \mu \mathrm{g} / \mathrm{ml} \mathrm{mAb}$ anti-X. After threefold washing and aspiration of the microtiter plate, two-times $100 \mu \mathrm{l}$ of these pre-incubated samples were added to adjacent wells. After 1-h incubation, the plate was washed threefold followed by aspiration and $100 \mu \mathrm{l}$ of Dig-labeled hsFc $\gamma$ RI $(0.5 \mu \mathrm{g} / \mathrm{ml})$ were added to each well. After an 1-h incubation and threefold washing followed by aspiration, $100 \mu \mathrm{l}$ anti-Dig-S-Fab-HRP conjugate $(50 \mathrm{mU} / \mathrm{ml})$ were added to each well and the plate was incubated again for $1 \mathrm{~h}$. After threefold washing and aspiration, ABTS $(100 \mu \mathrm{l}$ per well) was added and the color reaction was followed in the microplate reader.
Readout of the microtiter plate was performed as described for the bridging assay.

The cut-point was evaluated by analyzing 25 individual blank serum samples of either sex (a total 50 samples) in duplicates. Calculation of the cutpoint was performed using a non-parametric approach according to Shankar et al. [20]. To calculate platespecific cut-points, the plate-specific blank value was multiplied by the assay-specific normalization factor. In this study, two plates were used to generate data. The corresponding cut-points were $0.188 / 0.187$ OD.

\section{Analysis of drug tolerance}

Bridging and hsFc $\gamma$ RI-PG assays were performed in the presence of $\mathrm{mAb}$ anti-X using affinity-purified anti-idiotypic polyclonal rabbit Abs directed against

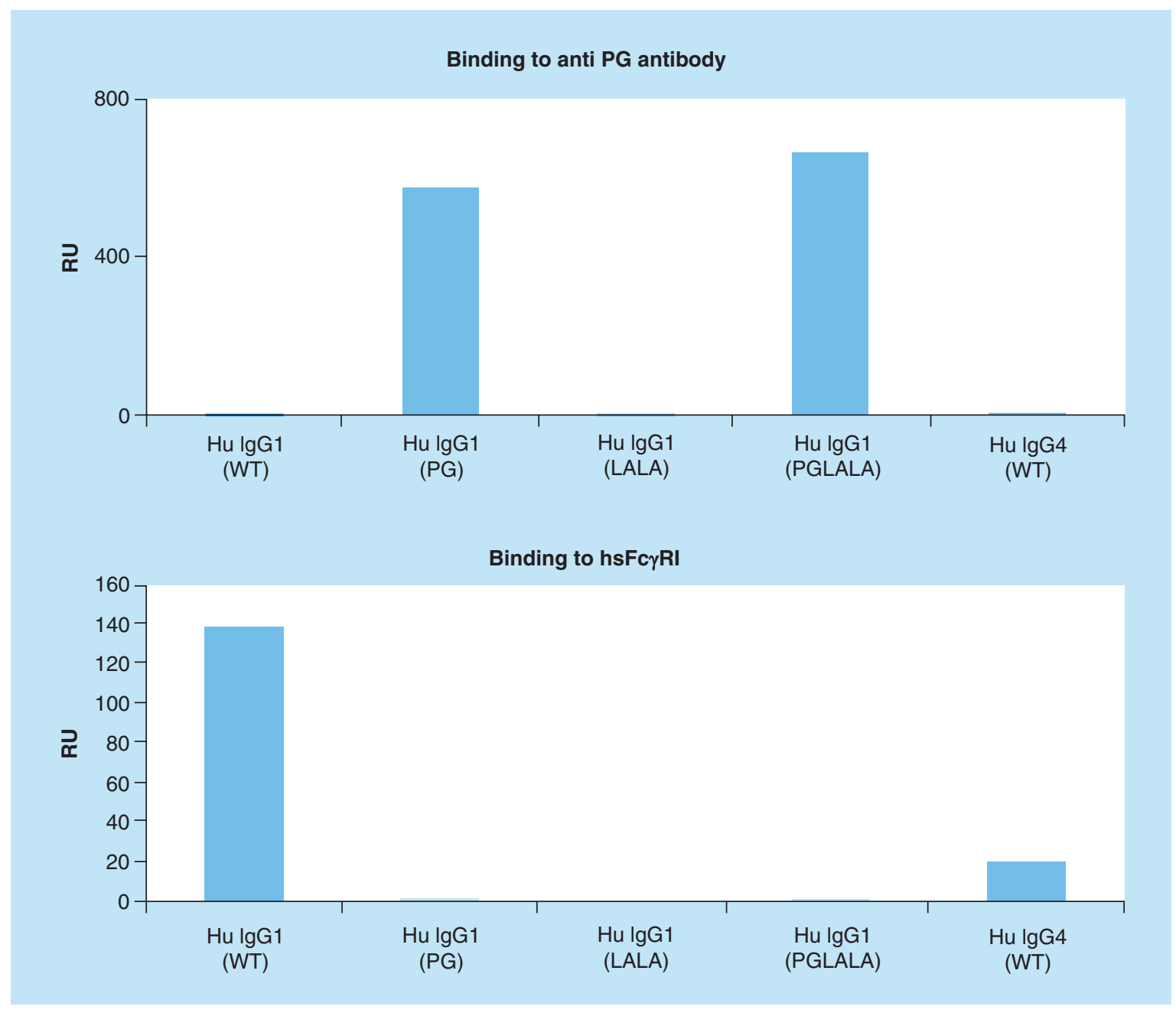

Figure 2. Specificity of anti-Pro329Gly monoclonal antibody and human soluble $\mathrm{Fc} \gamma$ receptor I binding as assessed by surface plasmon resonance. The binding specificity of anti-PG mAb and hsFc $\gamma \mathrm{RI}$ was tested for purified human wild-type IgG1, wild-type IgG4 and IgG subtypes with suppressed Fc effector functions (mutations PG, LALA, and PGLALA).

Hu: Human; hsFc RI: Human soluble Fc receptor I; LALA: Leu234Ala and Leu235Ala; mAb: Monoclonal antibody; PG: Pro329Gly substitution; RU: Relative units; WT: Wild-type. 
Table 1. Qualification data for the human soluble Fc $\gamma$ receptor I-Pro329Gly and bridging assays.

\begin{tabular}{|c|c|c|c|c|}
\hline \multirow[t]{2}{*}{ QC (assay concentration) } & \multicolumn{2}{|c|}{ hsFc $\gamma$ RI-PG assay } & \multicolumn{2}{|c|}{ Bridging assay } \\
\hline & 75 ng/ml (HQC) & $5.73 \mathrm{ng} / \mathrm{ml}(\mathrm{CPQC})$ & 154 ng/ml (HQC) & $1.89 \mathrm{ng} / \mathrm{ml}(\mathrm{CPQC})$ \\
\hline Intra-assay precision (\% CV) & 2 & 2 & 2.9 & 1.7 \\
\hline Interassay precision (\% CV) & 12 & 6 & 7.4 & 2.5 \\
\hline Drug tolerance factor & 833 & & 6 & \\
\hline Dilution factor & 50 (2\% serum) & & $10(10 \%$ serum $)$ & \\
\hline Normalization factor & 0.118 OD (additive) & & 0.054 OD (additive) & \\
\hline $\begin{array}{l}\text { Assay signal at screening cut point } \\
\text { (two plates) }\end{array}$ & $0.188 / 0.187$ OD & & $0.061 / 0.062$ OD & \\
\hline Estimated cut point sensitivity in serum & $5.73 \mathrm{ng} / \mathrm{ml}$ & & $1.89 \mathrm{ng} / \mathrm{ml}$ & \\
\hline
\end{tabular}

the complementarity determining region of $\mathrm{mAb}$ anti-X as a control ADA for the bridging assay and a conjugate of human wtIgG and human PG-modified IgG for the hsFc $\gamma$ RI-PG assay. The drug tolerance factor was calculated as the maximal ratio between the concentrations of the control ADA and $\mathrm{mAb}$ anti-X, at which a positive screening signal was still observed.

\section{Quantification of mAb anti-X}

Drug levels were measured with a solid-phase ELISA with a quantification range of $1.5-60 \mathrm{ng} / \mathrm{ml}$. Briefly, a biotinylated anti-idiotype antibody was immobilized on a streptavidin-coated MTP to capture the anti-X antibody. Bound drug was detected by a dioxygenylated anti-X detection reagent and anti-Digoxygenin antibody peroxidase conjugate. ABTS was used as a substrate to generate a color reaction, which was photometrically assessed at $405 \mathrm{~nm}$ (reference wavelength $490 \mathrm{~nm}$ ).

\section{Human study samples}

Samples were obtained from eight patients who had received weekly or biweekly administrations of $\mathrm{mAb}$ anti-X (10 mg each dose). Blood samples were collected before and once daily after each dose. Blood samples were clotted for about $30 \mathrm{~min}$ at room temperature and were centrifuged within $1 \mathrm{~h}$ after blood collection at $1500 \times$ g. Serum fractions were collected and stored at $-70^{\circ} \mathrm{C}$ until analysis.

\section{Results \& discussion}

\section{Specificity of anti-PG mAb \& hsFc $\gamma R \mathrm{I}$}

We tested the binding specificity of the anti-PG $\mathrm{mAb}$ raised against PGLALA IgG1 to purified human wt IgG1, wtIgG4 and human IgG1 bearing PG, LALA or PGLALA mutations (Figure 2, upper panel). The antiPG mAb demonstrated a strong binding to PGLALA IgG1 and, to IgG1 carrying PG mutation only, with the signal for PG IgG1 being only slightly lower than that for PGLALA IgG1. The binding to IgG1 with PG mutations in the Fc region was specific, as no signal was detected for wtIgG1, wtIgG4 or LALA IgG1. Thus, although the anti-PG $\mathrm{mAb}$ was raised against PGLALA IgG1, it can be used for capturing both PG and PGLALA IgG1.

As expected [12], hsFcyRI binding to IgG1 bearing PG, LALA or PGLALA mutations was almost completely eliminated, whereas a strong signal was observed for human wtIgG1 (Figure 2, lower panel). Binding to wtIgG4 was weak in agreement to already published data $[21,22]$.

Overall, these results demonstrate appropriate specificity of the used capture and detection reagents and that we can largely exclude interference due to unspecific capture of WT antibodies by the anti-PG mAb or unspecific hsFc $\gamma$ RI binding to the captured drug.

\section{Assay qualification parameters for bridging} \& hsFc $\gamma$ RI-PG assays

The bridging and hsFc $\gamma$ RI-PG assays demonstrated comparable intra and interassay precision in the assay qualification for the use in human serum samples (Table 1). The hsFc $\gamma$ RI-PG had a slightly reduced interassay precision at high QC, yet all parameters were within the accepted deviation range $(\leq 20 \%)$. Both assays showed high and very similar intra-assay precision ( $\mathrm{CV} \leq 3 \%)$.

The dilution factor and the normalization factor for cut point (CP) were higher in the hsFc $\gamma$ RI-PG assay than in the bridging assay, indicating a slightly lower sensitivity.

Improved drug tolerance of the hsFc $\gamma$ RI-PG assay The drug tolerance factor for the hsFc $\gamma$ RI-PG assay was $833(30 \mathrm{ng} / \mathrm{ml}$ positive control was detected as positive in the presence of up to $25 \mu \mathrm{g} / \mathrm{ml} \mathrm{mAb}$ anti-X) as compared 
with approximately 6 for the bridging assay $(500 \mathrm{ng} / \mathrm{ml}$ positive control was detected as positive in the presence of up to $3 \mu \mathrm{g} / \mathrm{ml} \mathrm{mAb}$ anti-X). Although these experimental data were generated with two different positive controls, which only mimic real samples, the dramati- cally improved drug tolerance of the hsFc $\gamma$ RI-PG assay confirms our assumption that the assay setup is inherently resistant to interference by residual drug. Indeed, while the hsFc $\gamma$ RI-PG assay relies on the formation of a drug-ADA complex with the residual drug acting as a

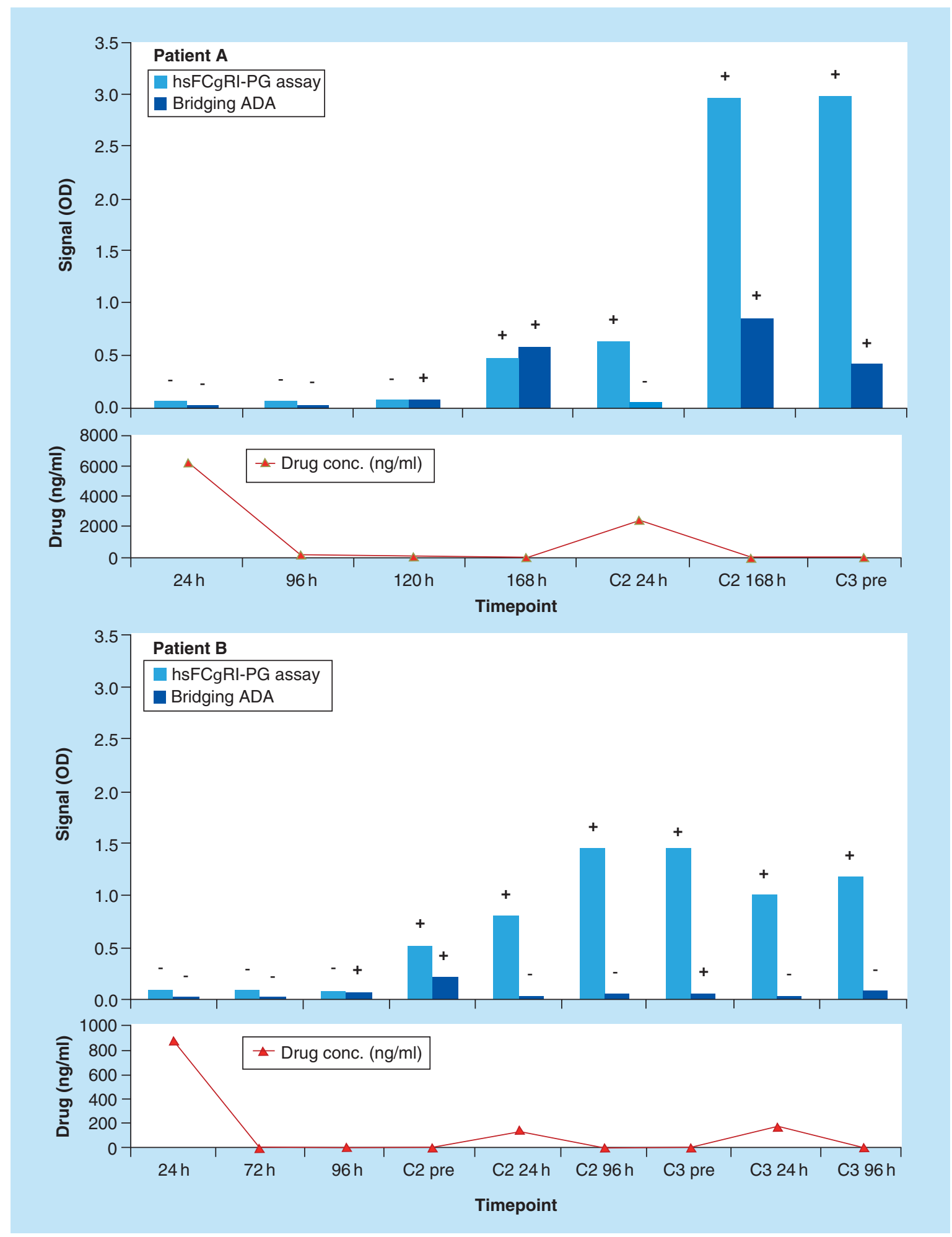




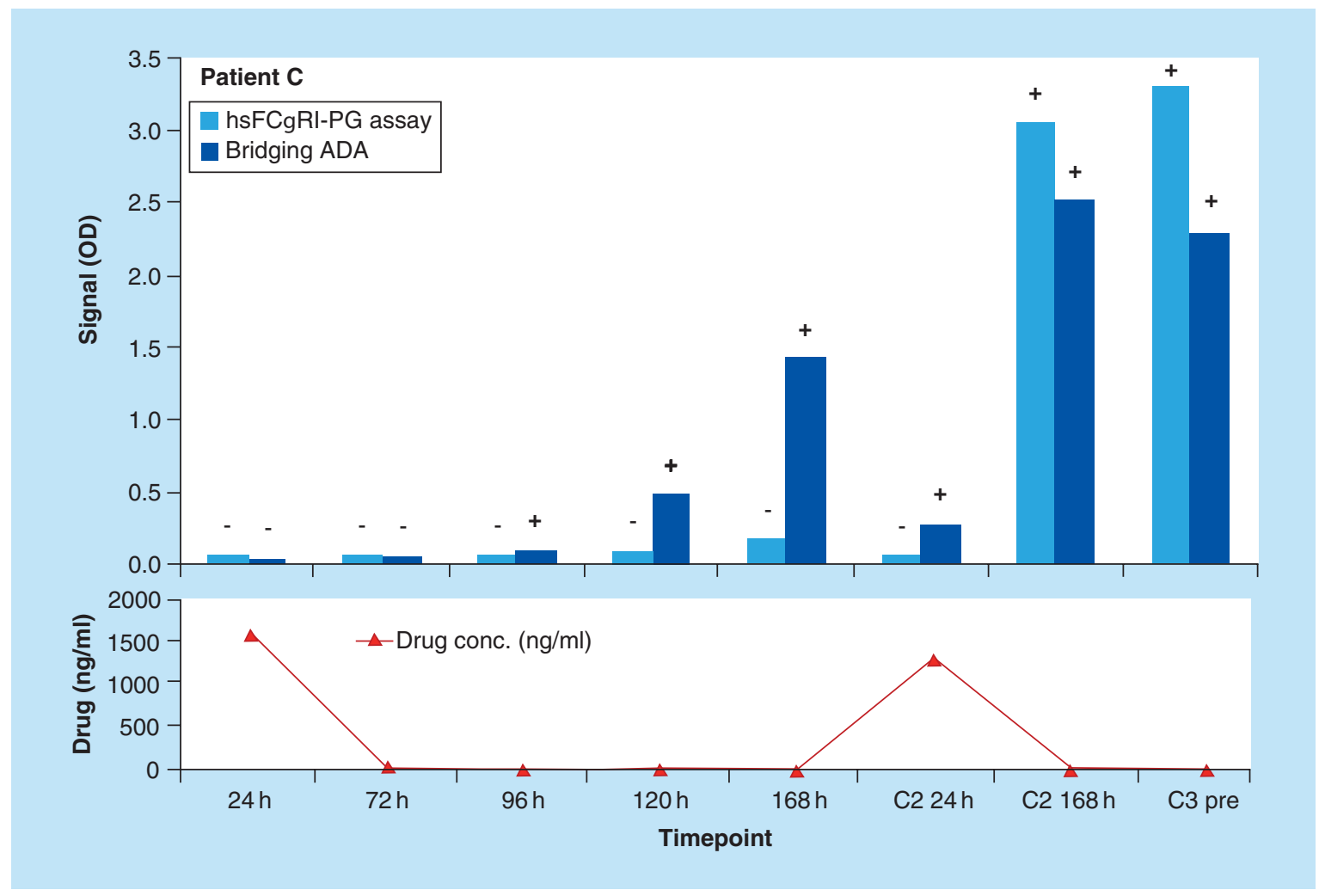

Figure 3. Time course of antidrug antibody detection and drug concentration in three patients (cont. from facing page). Patients received biweekly (A \& C) or weekly administration (B) of the therapeutic antibody $m A b$ anti-X (10 mg each dose). Samples were tested for antidrug antibodies by both the bridging and the hsFcyRI-PG assays. -: ADA negative; +: ADA positive; ADA: Anti-drug antibody; C2: Second treatment cycle; C3: Third treatment cycle; mAb: Monoclonal antibody; OD: Optical density; pre: Predose.

signal enhancer, the bridging assay is negatively affected by residual drug, which can even lead to false-negative results at high drug concentrations (Figure 1).

\section{Comparison of bridging \& hsFcyRI-PG assays in human study samples}

We assessed the performance of the assays in serum samples obtained from eight patients who had received weekly or biweekly administrations of $10 \mathrm{mg} \mathrm{mAb}$ anti-X (Table 2). In the bridging assay, seven patients were tested ADA-positive as compared with eight patients in the hsFc $\gamma$ RI-PG assay. Both assays demonstrated similar qualitative results for about $71 \%$ of the investigated samples. For $29 \%$ of the samples, different results were obtained with both assays (Figure 3 ). Below, we discuss possible interpretations and the impact on the applicability of the assays.

The onset of the immune response was detected earlier by the bridging assay (Table 2 \& Figure 3) than by the hsFc $\gamma$ RI-PG assay in five of eight patients, with the especially striking difference being observed in Patient C (Figure 3C). This finding is in line with the previous observations [12] and most likely reflects early IgM-driven response [23], which cannot be detected by the hsFc $\gamma R I$ I-based assays [24]. Of note, the hsFc $\gamma$ RI-PG assay produced negative results for the late samples of Patient D (Table 2), suggesting a mixed IgM-IgG response with a predominant proportion of IgM in this patient without undergoing the usually observed class switch during immune response maturation [23].

At later time points, the hsFc $\gamma$ RI-PG assay showed a higher and more reliable detection rate than the bridging assay (Table 2). The reliability of the hsFc $\gamma$ RI-PG assay was most prominent in first post-dose samples after the second and third dosing, which were tested ADA-negative by the bridging assay (see also Figure 3). The failure of the bridging assay to detect ADA correlated with detectable drug concentration in these samples, thus again demonstrating high drug tolerance of the hsFc $\gamma$ RI-PG assay. It is worth noting that the presence of residual drug did not affect the qualitative results of the bridging assay in patients with high ADA concentrations (Table 2, patients $C, G$ and $H$ ), because the ADA signal, although clearly decreased, remained above the cut point (Figure 3C \& Supplementary Material).

The hsFc $\gamma$ RI-PG assay also showed a higher detection rate and higher signal in the late postdose 


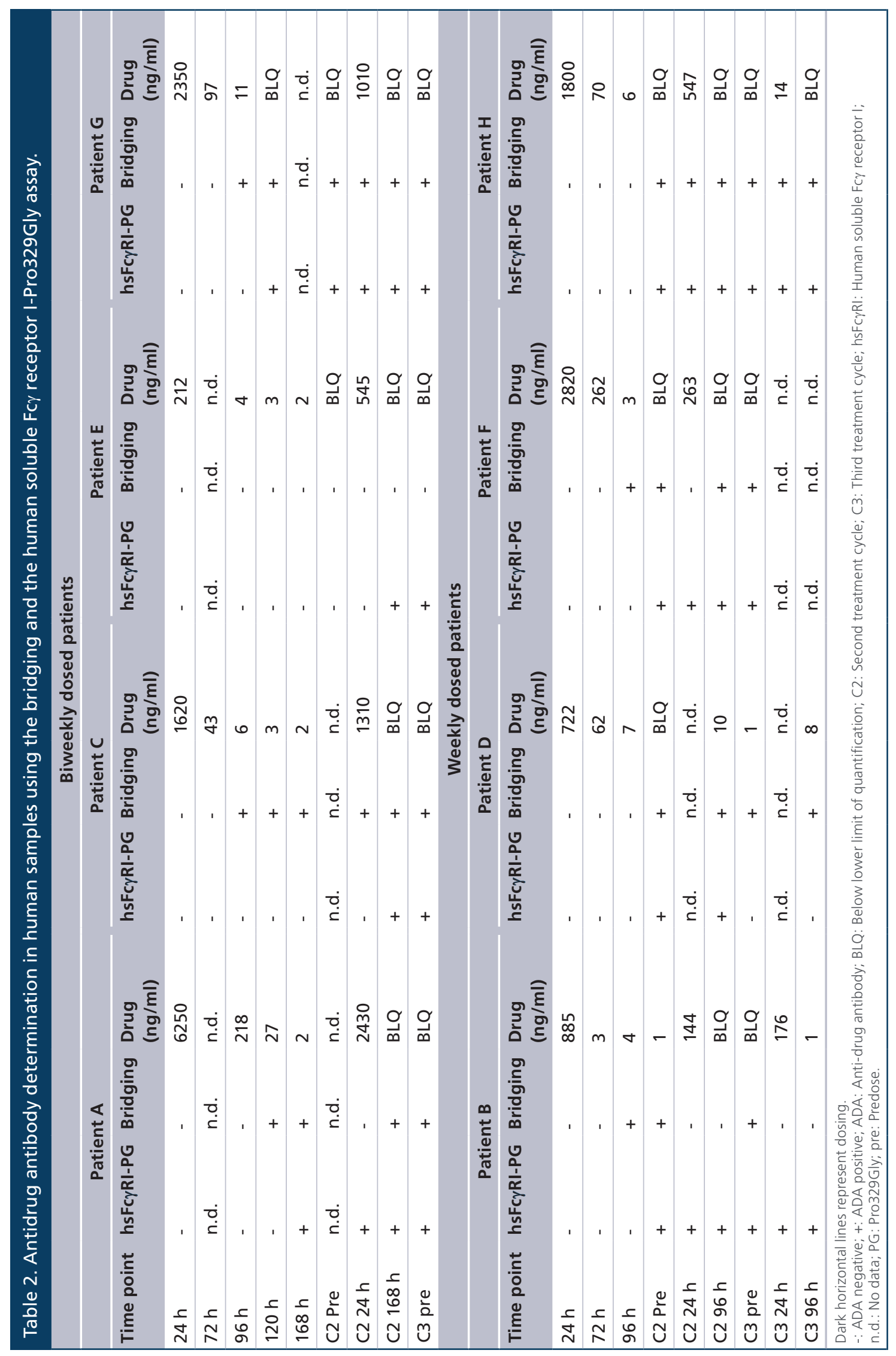


samples with drug concentrations below quantification level (Figure 3), which was evident in patient $\mathrm{B}$ (Table 2 \& Figure 3B) and especially in patient $\mathrm{E}$ (Table 2). Together with the higher dilution factor for the hsFc $\gamma$ RI-PG assay (Table 1), these results may indicate a better sensitivity of the hsFc $\gamma$ RI-PG assay despite the higher normalization factor. However, no definitive conclusion can be drawn on the basis of these data due to the variety of factors that can influence the sensitivity of the assays, such as drug concentration or patient's specific isotype composition of ADA.

\section{Overall assay comparison}

The standard bridging and hsFc $\gamma$ RI-PG assays differ in both the capturing and detection principle. In the bridging assay, drug-free ADAs are captured and detected by two differently labeled drug molecules, whereas the hsFcrRI-PG assay uses an antibody against a modified Fc region of the drug to capture a drug-ADA complex, which is then detected by the hsFc $\gamma$ RI specific for wtIgG1. The drug-dependent detection and capture makes the bridging assay susceptible to the presence of oligomeric soluble target, which can mimic ADA-bridge and thereby lead to false-positive results, and to the presence of residual drug, which can prevent detection by occupying binding sites of ADA [5-8]. In contrast, the hsFc $\gamma$ RI-based detection makes the hsFc $\gamma$ RI-PG assay tolerant to the presence of oligomeric soluble target [12], while the overall assay design that aims at the detection of drug-ADA complexes precludes the interference by residual drug. In fact, the assay format includes sample pre-incubation with free drug, which enables the formation of drugADA complexes and thus ensures the measurement of total ADA, especially in samples with low levels of in vivo-formed drug-ADA complexes. The assay may also be beneficial for detection of low affinity ADAs, because it does not require stable binding of two drug molecules.

However, the bridging assay is able to detect ADA of various Ig-subtypes, including IgM, and is applicable to all kinds of therapeutic antibodies [6,9], while the hsFc $\gamma$ RI-PG assay does not recognize Ig-subtypes other than IgG1 and therefore cannot detect less mature, potentially transient, immune responses of the IgM-type. The hsFcyRI-PG assay is also limited to therapeutic antibodies bearing the PG modification within the Fc domain.

Overall, the hsFc $\gamma$ RI-PG assay represents a useful generic approach of immunogenicity testing for PGmodified antibodies. The assay can easily be adapted to different projects because it does not require labeled therapeutic mAb, which can especially be advantageous for complex antibodies (e.g., multivalent antibodies or antibody-drug conjugates). The hsFc $\gamma$ RI-PG assay is extremely tolerant to the presence of any serum factor that is able to bind two drug molecules, such as an oligomeric soluble target, providing direct evidence that the observed signal is indeed an antibody. It is also insensitive to the presence of residual drug and may have increased sensitivity for the late immune response. Its inability to detect IgM response can be beneficial for immunogenicity assessment in special populations, such as in patients with high levels of rheumatoid factor a composition of $\operatorname{IgM}$ antibodies that can be tested false positive in the bridging assays [25]. Although its specificity to $\operatorname{IgG1}$ is a significant limitation, it is worth noting that a typical immune response always switches to IgG1. Therefore, we assume that there will be detectable ADA for this assay in most practical situations $[23,26]$. Finally, applied in a combination with the bridging assay, the hsFc $\gamma$ RI-PG assay can allow a more detailed characterization of the immune response.

\section{Conclusion}

The novel hsFc $\gamma$ RI-based assay for IgG1 ADA detection can be considered a platform assay applicable for all therapeutic antibodies bearing the PG mutation in the Fc domain. The assay does not require labeled drug, detecting drug-ADA complexes using two assay-specific reagents: a Bi-labeled antibody directed against PG modified therapeutic mAbs and Dig-labeled hsFc $\gamma$ RI, which specifically detects human wtIgG1. When compared with the bridging assay in qualification exercises and clinical studies, the hsFc $\gamma$ RI-PG assay showed similar precision and markedly improved drug tolerance. The assay can complement the bridging assay in immunogenicity assessment, increasing the overall reliability of the ADA detection and providing additional information about the nature of immune response.

\section{Future perspective}

The hsFcrRI-PG assay can complement the bridging assay as orthogonal assay, increasing the overall reliability of the immunogenicity assessment of therapeutic $\mathrm{mAb}$ with suppressed $\mathrm{Fc}$ effector function. The combination of both analytical methods, as suggested, is especially beneficial for the analysis of samples containing high concentration of residual drug or oligomeric soluble targets, which cannot be reliably tested by the bridging assay alone. Moreover, the IgG1-specificity of the hsFc $\gamma$ RI-PG assay can help to further characterize the immunogenicity profile of therapeutic mAbs, for example, by differentiating 
between early IgM and late IgG responses. Performed without sample pre-incubation with free drug, the assay can detect pre-existing drug-ADA complexes (as opposed to total ADA detection described in this article) and thus contribute to a better understanding of adverse effects that result from the formation of immune complexes [27].

The assay can easily be adapted to any PG-modified therapeutic $\mathrm{mAb}$, as it does not require the generation of drug-dependent capture and detection reagents. The high-sequence homology of the $\mathrm{Fc}$ region between human and cynomolgus monkey $\operatorname{IgG}[28]$ allows the usage of the same assay for the analysis of preclinical and clinical samples [12]. In addition to the PG, several other Fc modifications affect the affinity of mAbs to both the Fc receptors and complement [16,29-31]. We believe that the assay principle can be transferred to other Fc mutations that allow the generation of specific Abs to be used similarly to the anti-PG mAb.

\section{Supplementary data}

To view the supplementary data that accompany this paper please visit the journal website at: www.future-science.com/ doi/full/10.4155/bio-2017-0048

\section{Acknowledgements}

The authors thank S Lang (Scientific \& Medical Writing) and A Nürnberg (Roche, Basel, Switzerland) for the diligent preparation of the manuscript.

Financial \& competing interests disclosure

The authors have no other relevant affiliations or financial involvement with any organization or entity with a financial interest in or financial conflict with the subject matter or materials discussed in the manuscript apart from those disclosed.

Writing assistance was funded by Roche Diagnostics $\mathrm{GmbH}$.

Ethical conduct of research

The authors state that they have obtained appropriate institutional review board approval or have followed the principles outlined in the Declaration of Helsinki for all human or animal experimental investigations. In addition, for investigations involving human subjects, informed consent has been obtained from the participants involved.

\section{Open access}

This work is licensed under the Attribution-NonCommercialNoDerivatives 4.0 Unported License. To view a copy of this license, visit http://creativecommons.org/licenses/by-nc-nd/4.0/

\section{Executive summary}

- A novel assay to detect drug-antidrug antibody (ADA) complexes using anti-PG antibody for capture and human soluble Fc $\gamma$ receptor for detection was established. The human soluble Fcy receptor I-Pro329Gly (hsFcyRI-PG) assay represents a platform solution for all therapeutic antibodies bearing PG modification, which does not require specifically labeled therapeutics.

- A bridging assay will detect anything that binds two molecules of drug, in contrast, the hsFcgRI-PG assay confirms that the serum factor binding to drug is indeed an antibody.

- The hsFcrRI-PG assay was compared with a standard bridging assay. Both assays showed adequate results during assay qualification. The hsFcyRI-PG assay, however, demonstrated much higher drug tolerance than the bridging assay.

- The hsFc $\gamma$ RI-PG assay had high sensitivity to IgG1 ADAs, but was not able to detect early (IgM-based) immune responses in the analysis of human samples from a clinical study. In contrast, the assay was superior to the bridging assay in detecting ADAs in the presence of residual drug.

- The hsFc $\gamma$ RI-PG assay can be used as an orthogonal method complimentary to the standard bridging assay, but not as a solitary assay.

- A combination of the standard bridging assay with the hsFc $\gamma$ RI-PG assay can improve the reliability of immunogenicity assessment, especially in the presence of residual drug or oligomeric-soluble targets. The hsFcyRI-PG assay provides evidence that the detected signal is caused by an IgG1 antibody. It can also allow a more detailed characterization of the immunogenicity response to therapeutic monoclonal antibodies containing PG mutation in the Fc domain with respect to the immunoglobulin subclass.

\section{References}

Papers of special note have been highlighted as:

- of interest; $\bullet$ of considerable interest

1 Koren E, Smith HW, Shores E et al. Recommendations on risk-based strategies for detection and characterization of antibodies against biotechnology products. J. Immunol. Methods 333(1-2), 1-9 (2008).

2 Guideline on Immunogenicity Assessment of Monoclonal Antibodies Intended for in vivo Clinical Use. European
Medicines Agency and Committee for Medicinal Products for Human Use, CHMP (2012).

www.ema.europa.eu/docs/

3 Wang YM, Jawa V, Ma M. Immunogenicity and PK/PD evaluation in biotherapeutic drug development: scientific considerations for bioanalytical methods and data analysis. Bioanalysis 6(1), 79-87 (2014).

4 Mikulskis A, Yeung D, Subramanyam M, Amaravadi L. Solution ELISA as a platform of choice for development of 
robust, drug tolerant immunogenicity assays in support of drug development. J. Immunol. Methods 365(1-2), 38-49 (2011).

5 Bautista AC, Wullner D, Moxness M, Swanson SJ, Chirmule $\mathrm{N}$, Jawa V. Impact of matrix-associated soluble factors on the specificity of the immunogenicity assessment. Bioanalysis 2(4), 721-731 (2010).

6 Mire-Sluis AR, Barrett YC, Devanarayan V et al. Recommendations for the design and optimization of immunoassays used in the detection of host antibodies against biotechnology products. J. Immunol. Methods 289(1-2), 1-16 (2004).

7 Weeraratne DK, Lofgren J, Dinnogen S, Swanson SJ, Zhong ZD. Development of a biosensor-based immunogenicity assay capable of blocking soluble drug target interference. J. Immunol. Methods 396(1-2), 44-55 (2013).

8 Zhong ZD, Dinnogen S, Hokom M et al. Identification and inhibition of drug target interference in immunogenicity assays. J. Immunol. Methods 355(1-2), 21-28 (2010).

9 Geng D, Shankar G, Schantz A, Rajadhyaksha M, Davis $\mathrm{H}$, Wagner C. Validation of immunoassays used to assess immunogenicity to therapeutic monoclonal antibodies. J. Pharm. Biomed. Anal. 39(3-4), 364-375 (2005).

10 Pierog P, Krishna M, Yamniuk A, Chauhan A, DeSilva B. Detection of drug specific circulating immune complexes from in vivo cynomolgus monkey serum samples. J. Immunol. Methods 416, 124-136 (2015).

11 Stubenrauch K, Wessels U, Essig U, Vogel R, Schleypen J. Evaluation of a generic immunoassay with drug tolerance to detect immune complexes in serum samples from cynomolgus monkeys after administration of human antibodies. J. Pharm. Biomed. Anal. 52(2), 249-254 (2010).

12 Wessels U, Poehler A, Moheysen-Zadeh M et al. Detection of ADAs against human therapeutic antibodies lacking Fceffector functions by usage of soluble Fcgamma Receptor I (submitted). Bioanalysis 8(20), 2135-2145 (2016).

-• Describes the assay that uses the same detection reagent (hFCyRI) as in the assay reported here. The drug-independent detection provides similar advantages, in particular an improved resistance against oligomeric target interference.

13 Bruhns P, Iannascoli B, England P et al. Specificity and affinity of human Fcgamma receptors and their polymorphic variants for human IgG subclasses. Blood 113(16), 3716-3725 (2009).

14 Bacac M, Fauti T, Sam J et al. A novel carcinoembryonic antigen T-cell bispecific antibody (CEA TCB) for the treatment of solid tumors. Clin. Cancer Res. (2016).

15 Baehner M. WO2012130831A1 (2012).

Moore GL, Chen H, Karki S, Lazar GA. Engineered Fc variant antibodies with enhanced ability to recruit complement and mediate effector functions. mAbs 2(2), 181-189 (2010).

17 Stubenrauch K, Mackeben K, Vogel R, Heinrich J. Generic anti-drug antibody assay with drug tolerance in serum samples from mice exposed to human antibodies. Anal. Biochem. 430(2), 193-199 (2012).

18 Carrasco-Triguero M, Davis H, Zhu Y et al. Application of a plug-and-play immunogenicity assay in cynomolgus monkey serum for ADCs at early stages of drug development. J. Immunol. Res. 2016, 2618575 (2016).
-. Reports in References $[11,17,18]$ present similar assay principles based on the detection of drug-ADA complexes. All assays show the benefits that result from this format, especially an improved drug tolerance.

19 Staack RF, Stracke JO, Stubenrauch K, Vogel R, Schleypen J, Papadimitriou A. Quality requirements for critical assay reagents used in bioanalysis of therapeutic proteins: what bioanalysts should know about their reagents. Bioanalysis 3(5), 523-534 (2011).

20 Shankar G, Devanarayan V, Amaravadi L et al. Recommendations for the validation of immunoassays used for detection of host antibodies against biotechnology products. J. Pharm. Biomed. Anal. 48(5), 1267-1281 (2008).

21 Mancardi DA, Albanesi M, Jonsson F et al. The highaffinity human IgG receptor FcgammaRI (CD64) promotes IgG-mediated inflammation, anaphylaxis, and antitumor immunotherapy. Blood 121(9), 1563-1573 (2013).

22 van der Poel CE, Spaapen RM, van de Winkel JG, Leusen JH. Functional characteristics of the high affinity IgG receptor, FcgammaRI. J. Immunol. 186(5), 2699-2704 (2011).

23 Stewart JJ, Vahadji C, Seiden PE. The emergent dynamics of isotype switch. Autoimmunity 44(4), 294-303 (2011).

24 Fridman WH. Fc receptors and immunoglobulin binding factors. FASEB J. 5(12), 2684-2690 (1991).

25 Stubenrauch K, Wessels U, Birnboeck H, Ramirez F, Jahreis A, Schleypen J. Subset analysis of patients experiencing clinical events of a potentially immunogenic nature in the pivotal clinical trials of tocilizumab for rheumatoid arthritis: Evaluation of an antidrug antibody ELISA using clinical adverse event-driven immunogenicity testing. Clin. Ther. 32(9), 1597-1609 (2010).

26 Vidarsson G, Dekkers G, Rispens T. IgG subclasses and allotypes: from structure to effector functions. Front Immunol. 5, 520 (2014)

27 Krishna M, Nadler SG. Immunogenicity to biotherapeutics - the role of anti-drug immune complexes. Front. Immunol. 7, 21 (2016).

28 Jacobsen FW, Padaki R, Morris AE et al. Molecular and functional characterization of cynomolgus monkey IgG subclasses. J. Immunol. 186(1), 341-349 (2011).

29 Richards JO, Karki S, Lazar GA, Chen H, Dang W, Desjarlais JR. Optimization of antibody binding to FcgammaRIIa enhances macrophage phagocytosis of tumor cells. Mol. Cancer Ther. 7(8), 2517-2527 (2008).

30 Lazar GA, Dang W, Karki S et al. Engineered antibody Fc variants with enhanced effector function. Proc. Natl Acad. Sci. USA 103(11), 4005-4010 (2006).

31 Schlothauer T, Herter S, Koller CF et al. Novel human IgG1 and IgG4 Fc-engineered antibodies with completely abolished immune effector functions. Protein Eng. Des. Sel. 29(10), 457-466 (2016).

- Focuses on the Pro329Gly modification of therapeutic antibodies drug and provides additional information about specificity and affinity of Fc-engineered antibodies to Fc receptors. 